Case report

Open Access

\title{
Glucosamine and chondroitin sulfate supplementation to treat symptomatic disc degeneration: Biochemical rationale and case report
}

\author{
Wim J van Blitterswijk*1, Jos CM van de Nes$^{2}$ and Paul IJM Wuisman ${ }^{3}$
}

Address: ${ }^{1}$ Division of Cellular Biochemistry, The Netherlands Cancer Institute (Antoni van Leeuwenhoek Hospital), Plesmanlaan 121, 1066CX Amsterdam, The Netherlands, ${ }^{2}$ Department of Neurology, Zeeuws-Vlaanderen Hospital, Terneuzen, The Netherlands and ${ }^{3}$ Department of Orthopedic Surgery, "Vrije Universiteit" Medical Center, Amsterdam, The Netherlands

Email: Wim J van Blitterswijk* - w.v.blitterswijk@nki.nl; Jos CM van de Nes - vdnes@planet.nl; Paul IJM Wuisman - orthop@vumc.nl

* Corresponding author

Published: 10 June 2003

BMC Complementary and Alternative Medicine 2003, 3:2
Received: 10 February 2003

Accepted: 10 June 2003

This article is available from: http://www.biomedcentral.com/l472-6882/3/2

(C) 2003 van Blitterswijk et al; licensee BioMed Central Ltd. This is an Open Access article: verbatim copying and redistribution of this article are permitted in all media for any purpose, provided this notice is preserved along with the article's original URL.

\begin{abstract}
Background: Glucosamine and chondroitin sulfate preparations are widely used as food supplements against osteoarthritis, but critics are skeptical about their efficacy, because of the lack of convincing clinical trials and a reasonable scientific rationale for the use of these nutraceuticals. Most trials were on osteoarthritis of the knee, while virtually no documentation exists on spinal disc degeneration. The purpose of this article is to highlight the potential of these food additives against cartilage degeneration in general, and against symptomatic spinal disc degeneration in particular, as is illustrated by a case report. The water content of the intervertebral disc is a reliable measure of its degeneration/ regeneration status, and can be objectively determined by Magnetic Resonance Imaging (MRI) signals.
\end{abstract}

Case presentation: Oral intake of glucosamine and chondroitin sulfate for two years associated with disk recovery (brightening of MRI signal) in a case of symptomatic spinal disc degeneration. We provide a biochemical explanation for the possible efficacy of these nutraceuticals. They are bioavailable to cartilage chondrocytes, may stimulate the biosynthesis and inhibit the breakdown of their extracellular matrix proteoglycans.

Conclusion: The case suggests that long-term glucosamine and chondroitin sulfate intake may counteract symptomatic spinal disc degeneration, particularly at an early stage. However, definite proof requires well-conducted clinical trials with these food supplements, in which disc de-/ regeneration can be objectively determined by MRI. A number of biochemical reasons (that mechanistically need to be further resolved) explain why these agents may have cartilage structureand symptom-modifying effects, suggesting their therapeutic efficacy against osteoarthritis in general.

\section{Background}

Lower back pain caused by disc cartilage degeneration negatively affects quality of life and imposes an enormous financial burden. The intervertebral disc consists of two distinct regions: the outer series of concentric lamellae of organized collagen fibrils, known collectively as the annulus fibrosus, and the inner nucleus pulposus having a more random collagen organization and an abundance of 
aggregating proteoglycans. Degeneration and age-related changes in macroscopic, histologic and biochemical composition and structure of the annulus fibrosus and of the nucleus pulposus have been widely reported [1-7]. Until recently, interventions of degenerative disorders of the spine have focused on removal of the disc rather than its repair, which would be the preferred medical action. In the early stages of disc degeneration, when the degeneration is mostly confined to the nucleus, restore of nucleus pulposus normal function or slow down of its degenerative process (matrix breakdown) by providing certain well-rationalized nutraceuticals may be an attractive approach.

In this regard, the use of natural glucosamine and chondroitin sulfate (CS) as food additives against degeneration of articular cartilage at other locations has recently received much attention [8-16]. Most emphasis was laid upon the reported beneficial effect of glucosamine and CS on osteoarthritis of the knee, and the general conclusion was that the results were promising but the evidence insufficient. A major concern was the poor quality of the primary studies, some of which may have been biased by company sponsorship [8]. Another weak point was the variable/questionable quality of some of these food supplements. Despite these concerns, one may be impressed by the large number of papers (more than a hundred; only a few cited here) that almost without exception reported beneficial effects of these supplements in osteoarthritis patients, horses and small animals. Glucosamine as well as CS, alone or in combination, appeared effective against osteoarthritis of the knee (by far the most studies [9-11]), finger joints $[17,18]$ and hip [17], and may thus possibly have beneficial effects on cartilage of all joints, including the intervertebral disc. Remarkably, a clear biochemical rationale behind the reported effects of glucosamine and $\mathrm{CS}$ is lacking in the literature.

Here we report on a case of symptomatic spinal disc degeneration, in which oral intake of regular doses of glucosamine and CS for two years may have promoted cartilage regeneration of a partly degenerated intervertebral disc. In addition, we discuss the biochemistry of cartilage degeneration and of possible regeneration by these supplements. Matrix repair is feasible at early stages of degradation [19] and involves restoration of glycosaminoglycan structure and associated water content (to be discussed below). This is most easily monitored by magnetic resonance imaging, particularly T2-weighted MRI [20]. Sequential MRI-imaging studies have recently likewise been employed successfully in longitudinal studies of lumbar disc degeneration [21] and to monitor healing of fractured and herniated intervertebral discs [22,23]. The present case report shows, for the first time, MRI data on the lumbar spine following oral intake of a supplement of glucosamine and CS.

\section{Case presentation}

A 56 year-old man presented in September 1999 with frequent/recurrent low-back pain and ischialgic complaints, which existed for more than 15 years. His lumbar mobility was maintained by daily moderate physical exercises and free-time sport (tennis). He continued these activities when he volunteered to take a daily glucosamine- and CSbased food supplement, capsules of Cosamin ${ }^{\circledast}$ DS (Nutramax Laboratories, Inc., Edgewood, MD), for two years. Each capsule contained $500 \mathrm{mg}$ glucosamine. $\mathrm{HCl}$ (FCHG49 ${ }^{\circledR}$ ) and $400 \mathrm{mg}$ of $95 \%$ low molecular weight (16 $\mathrm{kDa})$ sodium chondroitin sulfate (TRH122 ${ }^{\circledast}$; purified from bovine trachea), and $66 \mathrm{mg}$ manganese ascorbate (an essential cofactor for glycosyltransferases in proteoglycan biosynthesis). The patient took 3 capsules ( 2 in the morning, one in the evening) during the first 9 months; and 2 capsules (in the morning) for the remainder of the 2 yrs period.

\section{Clinical finding}

The patient felt a gradual improvement of the range of motion and functioning of his back, with less pain, starting about 6 months after first supplement intake. At the end of the 2 years period, his back felt stronger and more flexible, and was capable of withstanding heavier work loads without pain. Apart from this improvement, the overall physical condition of the patient remained unchanged during this period. Of note, the patient did not experience any adverse effect of these nutraceuticals.

\section{Magnetic resonance imaging finding}

MR imaging, using a $1.5 \mathrm{~T}$ Somatom machine (Siemens, Erlangen, Germany), on the lumbar spine was performed at the onset and after one and two years of supplement intake. To exclude possible diurnal variation of the disc water content, MRIs were taken at the same time of the day (in the morning). Imaging parameters were the following: T2-weighted sequence (turbo spin echo), spine array coil, repetition time $4000 \mathrm{~ms}$, echo time $90 \mathrm{~ms}$, slice thickness $4 \mathrm{~mm}$, separation between slices $0.4 \mathrm{~mm}$, inplane matrix $512 \times 512$ pixels, in-plane pixel size $0.8 \mathrm{~mm}$ $\times 0.8 \mathrm{~mm}$.

During the two years time period, improvement of the structural quality of the disc cartilage (associated with increased water content) was clearly visible by brightening of the T2-weighted MRI signal, as shown in Figure 1. The L3-4 disc showed an initial protrusion, which decreased in time, while the MRI signal normalized in time. During the two years, L3-4 disc height restored slightly (5-10\%). Disc L4-5 showed signs of an advanced state of degeneration, and no improvement but also no worsening of this disc 


\section{9}
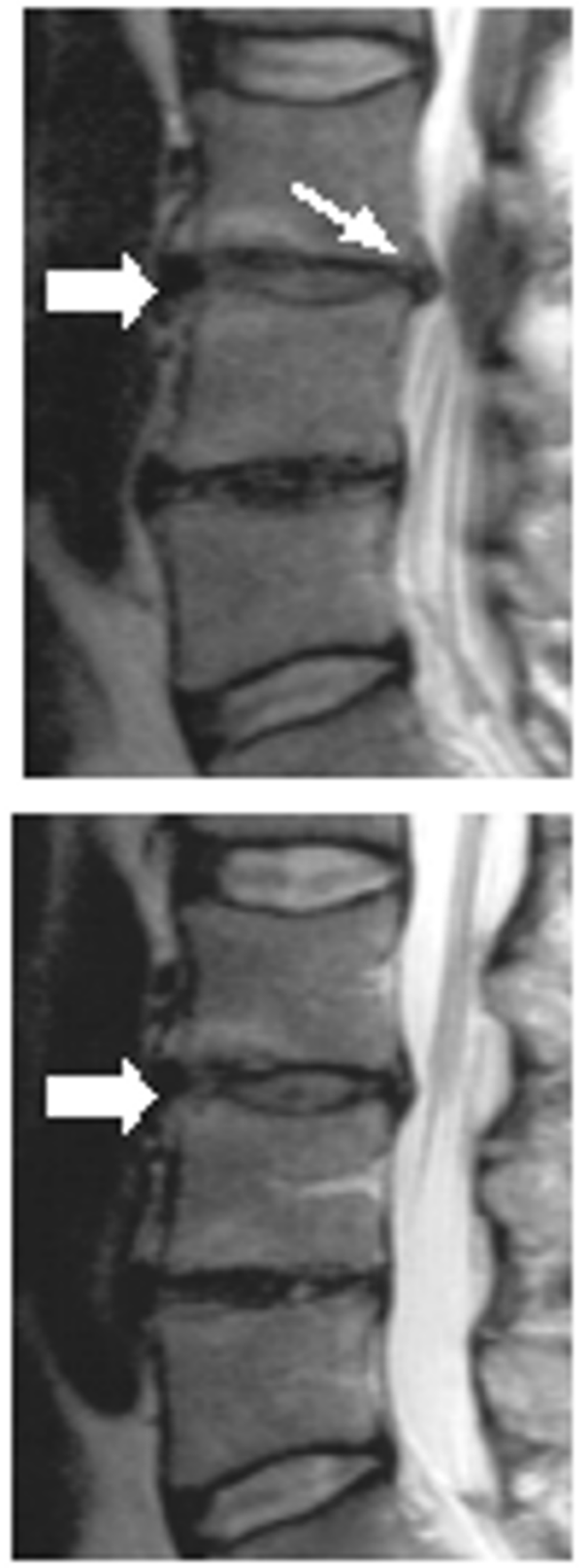

\section{0}
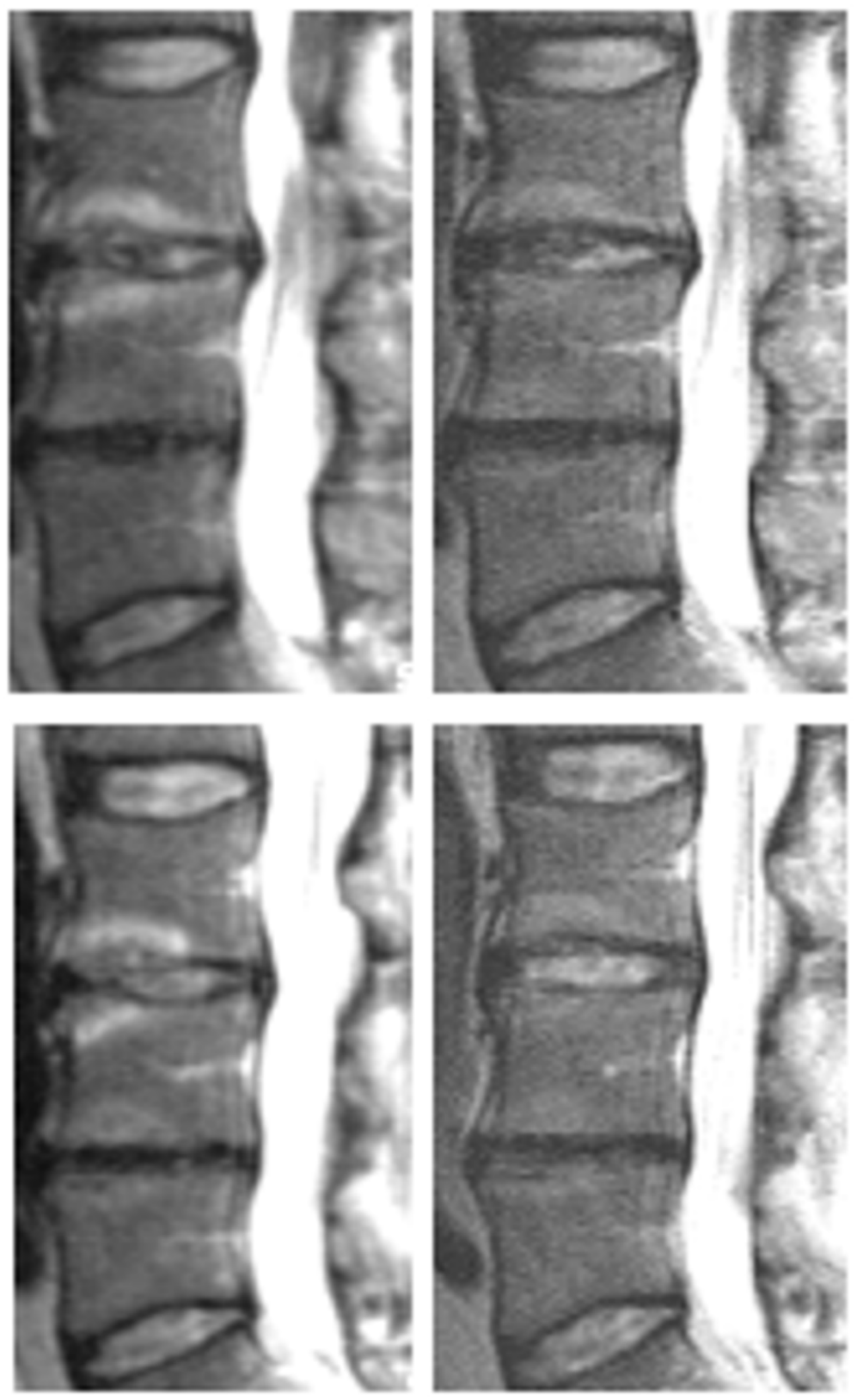

\section{1}

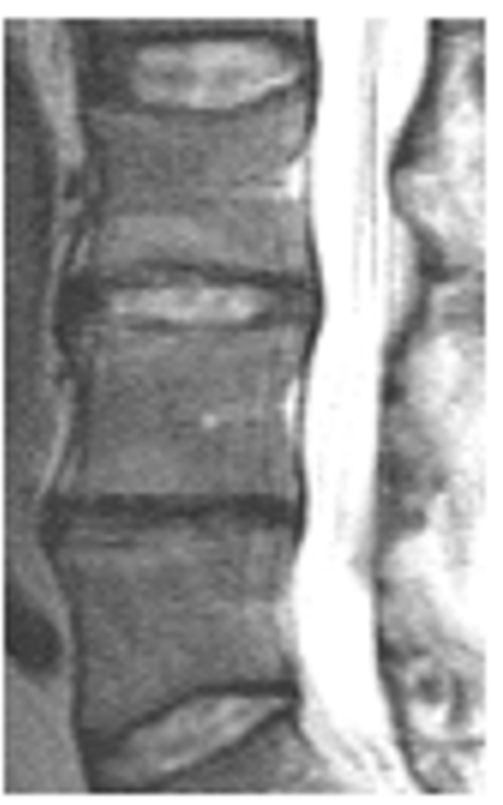

\section{Figure I}

Disc cartilage regeneration during 2 years of supplement intake. T2-weighted MR images of lumbar spine, made in September 1999 (start of supplement intake), 2000 and 200I. Note the increase of MRI signal of disc L3-4 (thick arrows) and disappearance of focal disc protrusion (thin arrow) of this disc. Note that the fully degenerated L4-5 disc remains unchanged. Upper panels and lower panels represent two consecutive images of planes $4 \mathrm{~mm}$ apart. 
(endplates morphologically unchanged) over the 2 years period.

\section{Discussion of MRI finding}

This case report illustrates the value of MRI to monitor disc quality improvement in the lumbar spine. After oral intake of glucosamine and CS for two years, an increased water retention (and less bulging/protrusion) in the partially degenerated L3-4 disc was seen, but not in the almost fully degenerated L4-5 disc, where probably little or no functional chondrocytes are left. These findings agree with a clinical study where radiographically mild forms of knee osteoarthritis showed significant improvement by supplement intake, while severe osteoarthritis did not [24]. Likewise, in (explant) tissue culture, the capacity for cartilage recovery after interleukin-1-induced matrix degradation was inversely related to the severity of degradation [19].

Of course, a single case reported does not prove that the nutraceuticals have caused the remarkable disc improvement. Recovery sometimes happens spontaneously and/ or concomitant with an improval of overall physical condition (although the latter is not true in the present case). Normalizing MRI signals have, for example, also been described in a case of spontaneously healed herniated discs [23]. Yet, it is unlikely that a disc recovery to an extent shown in Figure 1 would have happened spontaneously at an age of almost 60 year, and by chance concomitant with the supplement intake. Usually, degenerative disc changes have been shown (also by MRI) to be agerelated and progressive, and may even be present in almost all normal (asymptomatic) individuals older than 50 years $[7,25]$.

That glucosamine and CS might have a beneficial effect on degenerating discs is in line with the many papers suggesting such positive effects on cartilage degeneration (osteoarthritis) in general [8-16]. Further support is derived from a review of recent biochemical data, to be discussed below.

\section{Biochemical and physiological background of interverte- bral disc degeneration}

The intervertebral disc consists of a central, deformable nucleus pulposus, and an outer ring of concentric, collagen-rich lamellae known as the annulus fibrosis. The nucleus pulposus mainly consists of a complex extracellular matrix deposited by relatively few cells, the chondrocytes. The matrix in dics resembles that in other articular cartilages, being composed of hyaluran-bound proteoglycans, strengthened by collagen fibres $[26,27]$. Most of the matrix mass consists of glycosaminoglycans (GAGs), i.e. very long chains of sugar units, negatively charged by many carboxyl- and sulfate groups. These charged groups are neutralized by cations, which, in turn, attract and retain large quantities of water by osmotic forces. These forces equilibrate with the tensile forces of the collagen network and the external forces on the disks. The biochemical composition thus offers the central matrix the unique capacity to create a hydraulic space of fixed volume and alterable dimension. The proteoglycans undergo slow continual breakdown and renewal (turnover). The breakdown is accomplished by extracellular proteases such as aggrecanase [28] and metalloproteinases [29-33], while renewed synthesis occurs by the activity of, and within chondrocytes. During cartilage degeneration, metabolic turnover is increased and matrix degradation exceeds the de novo synthesis [34]. The result is a hypertrophic (chondroblastic) response of chondrocytes, and a progressive loss of proteoglycans [35], charged sulfate groups [36] and water retention.

Chondroitin sulfate (CS) is a repeating disaccharide unit in the GAG polymer. One of the sugars in this disaccharide is $\mathrm{N}$-acetylgalactosamine with sulfate groups at the 4 and/or 6 position of the hexose ring. Maturation and ageing causes a shift from 4- to 6-sulfation and a high degree of 4,6-disulfation at the GAG terminal residues, which is much decreased in degenerated cartilage [36]. Apparently, the hypermetabolic chondrocytes in degenerating discs have insufficient capacity to make functional full-size proteoglycans with the correct sulfation for sufficient water retention.

The intervertebral disc is avascular. Nutrition and stimulation of chondrocytes depends only on diffusion via two routes: the annular route, through which the disc receives nutrients directly from the surrounding vascular plexus, and the vertebral route through the endplates of the vertebral bodies, which are supplied with a capillary bed $[37,38]$. The relative importance of the two routes for disc metabolism remains undetermined. Nutrient diffusion is believed to be facilitated by moderate intermittent hydrostatic pressure, e.g. during physical exercise. However, excessive or prolonged load on the intervertebral joints may cause injuries that affect disc integrity. Disc degeneration commences around the vertebral endplate [3-5], often after impairment of the vascular bed system, which interrupts nutrition via the vertebral route [38]. Together with ageing and/or genetic factors, this promotes proteoglycan breakdown and other phenotypic changes in the disc $[33,39]$. The eventual result of this imbalance in molecular turnover is matrix resorption and dehydration of the nucleus and of the annulus fibrosus, resulting in reduction of disc height and further progression of the degeneration process, leading to clinical symptoms such as lower back pain. 


\section{Glucosamine and chondroitin sulfate may stimulate bio- synthesis and inhibit breakdown of proteoglycans in degenerated cartilage}

The inability of chondrocytes to make sufficient and fullsized extracellular matrix molecules may be caused by age-related dedifferentiation [40], conceivably with defects in the activity of specific glycosyl- and/or sulfotransferases that add sugar units, one by one, and sulfate groups to the growing GAG chains [41]. Alternatively, reduced nutrient sugar supply to chondrocytes may lead to a loss of proteoglycan production and disc degeneration [42], most probably caused by a shortage of appropriate sugar precursors that the cell normally makes itself for delivery to its own proteoglycan 'factory', the Golgi apparatus. If so, administration of pre-made, ready-to-use sugar units, such as glucosamine and CS, as a food supplement, could help, provided that sufficient amounts are absorbed and can reach, via the blood stream and the endplates, the GAG-producing machinery in chondrocyte's Golgi apparatus. The effect of these food supplements on cartilage proteoglycan synthesis should be most revealing under experimental conditions where proteoglycans undergo rapid replacement and endogenous precursors might therefore be limiting. For example, cartilage in (rabbit) knees has been damaged by chymopapain injection, and joint recovery (new synthesis of proteoglycans) was then studied with or without oral glucosamine treatment [43]. Glucosamine significantly increased the sulfated GAG content in these joints. This implies that glucosamine may likewise promote GAG synthesis in case of cartilage degeneration, characterized by high proteoglycan turnover. For CS (alone), experimental studies of this particular type have not been published, but orally administered radiolabeled CS was found back in synovial fluid and partly incorporated in joint cartilage [44].

Pharmacokinetic studies have been performed in animals and man. For CS, bioavailability ranged from 5-15\% [4446]. CS is administered at a relatively low molecular weight (14-17 kDa), important for gastrointestinal absorption $[44,46]$, and is further depolymerized but not completely degraded $[44,47,48]$. Peak levels of CS in plasma were reached between 2 and $5 \mathrm{hr}$ after oral administration of a single dose, and significant accumulation was found upon multiple dosing [45]. Glucosamine was better absorbed, reportedly about $90 \%$, leading to an absolute bioavailability of $12-44 \%[45,49]$. It was partly and persistently incorporated in articular cartilage $[10,49]$.

In vitro studies have confirmed that exogenous (radiolabeled) glucosamine and CS are both taken up by chondrocytes and indeed used to build their extracellular matrix $[47,50,51]$. Administration of sufficient glucosamine may boost GAG synthesis in degenerated chondrocytes if endogenous glucosamine is a limiting factor [43] and/or if glycosyltransferases are downregulated, e.g. by interleukin-1 $\beta$ [52]. In addition to that, it may be speculated that exogenous CS, with sulfate groups already attached, may help to restore the impaired sulfation of degenerated GAGs, provided that its $\mathrm{N}$-acetylgalactosamine-sulfate units are liberated in the cell and then serve as substrates for the glycosyltransferases in the Golgi. The latter is not unlikely since these enzymes can use more than one type of hexose unit [41]. However, this speculative idea needs experimental testing.

Glucosamine and CS may also be chondroprotective through inhibition of matrix breakdown. Glucosamine inhibits interleukin-1 $\beta$-induced proteoglycan catabolism by inhibition of the cleavage enzyme aggrecanase [28], and of the production of inflammatory mediators (prostaglandin E2, nitric oxide) [52-55] and metalloproteinases [52-54], and the downregulation of glucuronosyltransferase [52]. CS is anti-inflammatory and may inhibit several (cartilage-destructive) proteases and cytokines secreted by leukocytes and chondrocytes [10]. CS inhibited bradykinin- or chymopapain-induced proteoglycan depletion from articular cartilage (mimicking natural degeneration) $[56,57]$.

When combined, glucosamine and CS, in an animal osteoarthritis model, were more effective than the compounds alone [58]. Clinical studies in animals [59,60] and man $[24,61]$ have further indicated that the combination therapy is effective, and allows a significant drop in NSAID use by osteoarthritis patients.

From this fundamental overview, it may be concluded that oral glucosamine and CS can pass the gastrointestinal tract and can indeed reach articular cartilage, probably also intervertebral discs, where it may have at least a chondroprotective effect and, quite possibly, a regenerative effect. At the same time, however, it is fair to say that the biochemical details are still far from understood and need further investigation.

\section{Conclusions}

Numerous studies on these nutraceuticals related to cartilage degeneration reached the obvious conclusion that it is necessary to conduct more randomized double-blind, placebo-controlled trials [9-11,14-18]. In addition to that, we consider it also important to generate additional evidence, such as shown here, that directly relates to the structural improvement of cartilage by these nutraceuticals, both in animal models and in man. Restoration of the sulfated proteoglycan matrix leads to more water retention and, therefore, measuring the water content of cartilage is an indisputable quality measure. The technique suited for that purpose is T2-weighted MRI, as 
illustrated in Figure 1. More signal (brightness) means more water content!

Published (positive) effects of glucosamine or CS on joint structure and cartilage morphology in man have thus far been limited to osteoarthritis of the knee and finger joints $[13,18,62]$. These studies involved scanning electronmicroscopy [62], measurement of interarticular space and/or osteophyte appearance by X-rays $[13,18]$. The present case showed, for the first time, normalizing MRI signals of a degenerated disc in the lumbar spine, suggesting (but not proving) that, indeed, this food supplement may have gradually led to anatomic improvement of the disc.

Since discs are avascular and the compounds have to reach the chondrocytes via intermittent pressure-dependent diffusion, we surmise, in agreement with a recent study [21], that it may have been important that the patient maintained spine mobility by sport activities to facilitate disc regeneration.

Contrary to NSAIDs, no significant adverse clinical, hematological, hemostatic or other side effects were found in any clinical study using glucosamine and/or CS supplementation $[8-10,24]$. The present case is no exception in this regard. Contrary to degenerated cartilage, these dietary supplements had no apparent effects on normal cartilage metabolism, as determined by ex vivo ${ }^{35} \mathrm{~S}$ incorporation into GAGs, or ${ }^{35} \mathrm{~S}$ release from prelabeled cartilage explants [58]. This may suggest a tropism of these agents for cartilage in the reactive state, characterized by enhanced proteoglycan turnover [34]. Glucosamine/CS does not contribute to insulin resistance in diabetics $[10,63]$, probably because the pharmacokinetics and tissue distribution of glucosamine/CS and glucose are different [49].

In conclusion, we discussed the scientific rationale behind the therapeutic use of oral glucosamine and CS against cartilage degeneration, and illustrated the possible efficacy in a case of spinal disc degeneration. Evaluation by MRI is relatively simple and without burden to the patient since the technique is nondestructive and no contrast agents are needed. Therefore, it is justified to conduct more definitive trials focusing on (disc) cartilage morphology, to unambiguously prove or disprove the beneficial affects of these supplements. An objective analysis method, MRI, as shown here could further add credence to such studies.

\section{Competing interests}

None declared.

\section{Authors' contributions}

Author $1(\mathrm{WJvB})$ is a cell biologist/ biochemist (PhD). He took the initiative of this study and wrote the manuscript in close communication with the co-authors. Author 2 $(\mathrm{JCMvdN})$ is the practising neurologist (MD) who treated and clinically evaluated the patient. Author 3 (PIJMW) is a professor in orthopedic surgery (MD, $\mathrm{PhD}$ ) who provided addidional input in this study based on his recognized lumbar spine expertise.

\section{Acknowledgement}

We thank Kenneth G.A. Gilhuys for assistance in preparing the MRI figures.

Written consent was obtained from the patient for publication of the patient's details.

\section{References}

I. Antoniou J, Steffen T, Nelson F, Winterbottom N, Hollander AP, Poole RA, Aebi M and Alini M: The human lumbar intervertebral disc: evidence for changes in the biosynthesis and denaturation of the extracellular matrix with growth, maturation, ageing, and degeneration J Clin Invest 1996, 98:996-I003.

2. Cole TC, Ghosh P and Taylor TK: Variations of the proteoglycans of the canine intervertebral disc with ageing Biochim Biophys Acta 1986, 880:209-219.

3. Coventry MB, Ghormley RL and Kernohan JW: The intervertebral disc: its microscopic anatomy and pathology. I. Anatomy, development and pathology J Bone Joint Surg Am 1945, 27:105II 2.

4. Coventry MB, Ghormley RL and Kernohan JW: The intervertebral disc: its microscopic anatomy and pathology. II. Changes in the intervertebral disc concomittant with age $J$ Bone Joint Surg Am 1945, 27:233-247.

5. Coventry MB, Ghormley RL and Kernohan JW: The intervertebral disc: its microscopic anatomy and pathology. III. Pathologic changes in the intervertebral disc J Bone Joint Surg Am 1945, 27:460-474.

6. Lyons G, Eisenstein SM and Sweet MB: Biochemical changes in intervertebral disc degeneration Biochim Biophys Acta I98I, 673:443-453.

7. Miller JA, Schmatz $C$ and Schultz $A B$ : Lumbar disc degeneration: correlation with age, sex, and spine level in 600 autopsy specimens Spine 1988, I 3:173-178.

8. Chard J and Dieppe P: Glucosamine for osteoarthritis: magic, hype, or confusion? BMJ 200I, 322:|439-|440.

9. Deal CL and Moskowitz RW: Nutraceuticals as therapeutic agents in osteoarthritis. The role of glucosamine, chondroitin sulfate, and collagen hydrolysate Rheum Dis Clin North Am 1999, 25:379-395.

10. De los Reyes GC, Koda RT and Lien EJ: Glucosamin and chondroitin sulfates in the treatment of osteoarthritis: a survey Prog Drug Res 2000, 55:81-103.

II. McAlindon TE, La Valley MP, Gulin JP and Felson DT: Glucosamine and chondroitin for treatment of osteoarthritis. A systematic Quality assessment and meta-analysis JAMA 2000, 283:|469-|475.

12. McAlindon T: Glucosamin for osteoarthritis: dawn of a new era? Lancet 200I, 357:247-248.

13. Reginster JY, Deroisy R, Rovati LC, Lee RL, Lejeune E, Bruyere O, Giacovelli G, Henrotin Y, Dacre JE and Gossett C: Long-term effects of glucosamine sulfate on osteoarthritis progression: a randomised, placebo-controlled clinical trial Lancet 200I, 357:25I-256.

14. Towheed TE and Anastassiades TP: Glucosamine and chondroitin for treating symptoms of osteoarthritis. Evidence is widely touted but incomplete JAMA 2000, 283: | 483- | 484.

15. Leeb BF, Schweitzer H, Montag K and Smolen JS: A metaanalysis of chondroitin sulfate in the treatment of osteoarthritis J Rheumatol 2000, 27:205-2II. 
16. Towheed TE, Anastassiades TP, Shea B, Houpt J, Welch V and Hochberg MC: Glucosamine therapy for treating osteoarthritis (Cochrane Review) Cochrane Database Syst Rev 200I, I:CD002946.

17. Leeb BF, Petera P and Neumann K: Results of a multicenter study of chondroitin sulfate use in arthroses of the finger, knee and hip joints Wien Med Wochenschr 1996, I46:609-6I4.

18. Verbruggen G, Goemaere S and Veys EM: Systems to assess the progression of finger joint osteoarthritis and the effects of disease modifying osteoarthritis drugs Clin Rheumatol 2002, 2I:23I-343

19. Williams A, Oppenheimer RA, Gray ML and Burstein D: Differential recovery of glycosaminoglycan after IL-I-induced degradation of bovine articular cartilage depends on degree of degradation Arthritis Res Ther 2003, 5:R97-RI05.

20. Modic MT, Pavlicek W, Weinstein MA, Boumphrey F, Ngo F, Hardy $R$ and Duchesneau PM: Magnetic resonance imaging of intervertebral disk disease. Clinical and pulse sequence considerations Radiology 1984, I 52: I03-I II.

21. Elfering A, Semmer N, Birkhofer D, Zanetti M, Hodler J and Boos N: Risk factors for lumbar disk degeneration: a 5-year prospective MRI study in asymptomatic individuals Spine 2002, 27:125I34.

22. Furderer S, Wenda K, Thiem N, Hachenberger R and Eysel P: Traumatic intervertebral disc lesion-magnetic resonance imaging as a criterion for or against intervertebral fusion Eur Spine J 200I, I 0: I54-163.

23. Reyentovich $A$ and Abdu WA: Multiple independent, sequential, and spontaneously resolving lumbar intervertebral disc herniations: a case report Spine 2002, 27:549-553.

24. Das A Jr and Hammad TA: Efficacy of a combination of FCHG49 glucosamine hydrochloride, TRHI22 low molecular weight sodium chondroitin sulfate and manganese ascorbate in the management of knee osteoarthritis Osteoarthritis Cartilage 2000, 8:343-350.

25. Boden SD, McCowin PR, Davis DO, Dina TS, Mark AS and Wiesel S: Abnormal magnetic-resonance scans of the cervical spine in asymptomatic subjects. A prospective investigation J Bone Joint Surg Am 1990, 72: I I 78-I I84.

26. Hayes $A$, Benjamin $M$ and Ralphs JR: Extracellular matrix in development of the intervertebral disc Matrix Biol 200I, 20:107121 .

27. Heinegard D and Oldberg A: Structure and biology of cartilage and bone matrix noncollagenous macromolecules FASEB J 1989, 3:2042-205I.

28. Sandy JD, Gamett D, Thompson V and Verscharen C: Chondrocytemediated catabolism of aggrecan: aggrecanase-dependent cleavage induced by interleukin-I or retinoic acid can be inhibited by glucosamine Biochem J 1998, 335:59-66.

29. Caterson B, Flannery CR, Hughes CE and Little CB: Mechanisms involved in cartilage proteoglycan catabolism Matrix Biol 2000, 19:333-344.

30. Goupille P, Jayson MI, Valat JP and Freemont AJ: Matrix metalloproteinases: the clue to intervertebral disc degeneration? Spine 1998, 23:1612-1626.

31. Kang JD, Stefanovic-Racic M, Mclntyre LA, Georgescu HI and Evans $\mathrm{CH}$ : Toward a biochemical understanding of human intervertebral disc degeneration and herniation. Contributions of nitric oxide, interleukins, prostaglandin E2, and matrix metalloproteinases Spine 1997, 22: I065-I073.

32. Roberts S, Caterson B, Menage J, Evans EH, Jaffray DC and Eisenstein SM: Matrix metalloproteinases and aggrecanase: their role in disorders of the human intervertebral disc Spine 2000, 25:3005-3013.

33. Weiler C, Nerlich AG, Zipperer J, Bachmeier BE and Boos N: 2002 SSE Award Competition in Basic Science: Expression of major matrix metalloproteinases is associated with intervertebral disc degradation and resorption Eur Spine J 2002, I I :308320.

34. Taylor TK, Melrose J, Burkhardt D, Ghosh P, Claes LE, Kettler A and Wilke $\mathrm{HJ}$ : Spinal biomechanics and aging are major determinants of the proteoglycan metabolism of intervertebral disc cells Spine 2000, 25:3014-3020.

35. Pearce RH, Grimmer BJ and Adams ME: Degeneration and the chemical composition of the human intervertebral disk J Orthop Res 1987, 5:198-205.
36. Plaas AHK, West LA, Wong-Palms $S$ and Nelson FRT: Glycosaminoglycan sulfation in human osteoarthritis. Diseaserelated alterations at the non-reducing termini of chondroitin and dermatan sulfate I Biol Chem 1998, 273: I 2642-I 2649.

37. Nachemson A, Lewin T, Maroudas A and Freeman MA: In vitro diffusion of dye through the end-plates and annulus fibrosis of human lumbar intervertebral discs Acta Orthop Scand 1970, 4I:589-607.

38. Ogata $\mathrm{K}$ and Whiteside LA: Nutrition pathway of the intervertebral disc Spine 1981, 6:21 I-216.

39. Johnstone B and Blayliss MT: The large proteoglycans of the human intervertebral disc: Changes in their biosynthesis and structure with age, topography and pathology Spine 1995, 20:674-684

40. Okuda S, Myoui A, Ariga K, Nakase T, Yonenobu K and Yoshikawa $\mathrm{H}$ : Mechanisms of age-related decline in insulin-like growth factor-I dependent proteoglycan synthesis in rat intervertebral disc cells Spine 200I, 26:242I-2426.

4l. Sugahara $K$ and Kitagawa $H$ : Recent advances in the study of the biosynthesis and functions of sulfated glycosaminoglycans Curr Opin Struct Biol 2000, 10:5 18-527.

42. Horner HA and Urban JP: 200I Volvo Award Winner in Basic Science Studies: Effect of nutrient supply on the viability of cells from the nucleus pulposus of the intervertebral disc Spine 200I, 26:2543-2549.

43. Oegema TR Jr, Deloria LB, Sandy JD and Hart DA: Effect of oral glucosamine on cartilage and meniscus in normal and chymopapain-injected knees of young rabbits Arthritis Rheum 2002, 46:2495-2503.

44. Conte A, Volpi N, Palmieri L, Bahous I and Ronca G: Biochemical and pharmacokinetic aspects of oral treatment with chondroitin sulfate Arzneimittel forschung 1995, 45:918-925.

45. Adebowale A, Du J, Liang Z, Leslie JL and Eddington ND: The bioavailability and pharmacokinetics of glucosamine hydrochloride and low molecular weight chondroitin sulfate after single and multiple doses to beagle dogs Biopharm Drug Dispos 2002, 23:217-225.

46. Ronca $G$ and Conte A: Metabolic fate of partially depolymerized shark chondroitin sulfate in man Int $/$ Clin Pharmacol Res 1993, I3(Suppl):27-34.

47. Bali J-P, Cousse $\mathrm{H}$ and Neuzil E: Biochemical basis of the pharmacological action of chondroitin sulfates on the osteoarticular system Sem Arthritis Rheum 2001, 3 I:58-68.

48. Volpi N: Oral bioavailability of chondroitin sulfate (Condrosulf((R)) and its constituents in healthy male volunteers Osteoarthritis Cartilage 2002, I 0:768-77I.

49. Setnikar I and Rovati LC: Absorption, distribution, metabolism and excretion of glucosamine sulfate. A review Arzneimittel forschung 2001, 5 I:699-725.

50. Noyszewski EA, Wroblewski K, Dodge GR, Kudchodkar S, Beers ], Sarma AV and Reddy R: Preferential incorporation of glucosamine into galactosamine moieties of chondroitin sulfates in articular cartilage explants Arthritis Rheum 200I, 44: $1089-1095$.

51. Schwartz NB and Dorfman A: Stimulation of chondroitin sulfate proteoglycan production by chondrocytes in monolayer Connect Tissue Res 1975, 3: I 15-122.

52. Gouze JN, Bordji K, Gulberti S, Terlain B, Netter P, Magdalou J, Fournel-Gigleux $S$ and Ouzzine M: Interleukin- Ibeta downregulates the expression of glucuronosyltransferase I, a key enzyme priming glycosaminoglycan biosynthesis: influence of glucosamine on interleukin-Ibeta-mediated effects in rat chondrocytes Arthritis Rheum 200I, 44:35I-360.

53. Fenton JI, Chlebek-Brown KA, Peters TL, Caron JP and Orth MW Glucosamine- $\mathrm{HCl}$ reduces equine articular cartilage degradation in explant culture Osteoarthritis Cartilage 2000, 8:258-265.

54. Orth MW, Peters TL and Hawkins JN: Inhibition of articular cartilage degradation by glucosamine- $\mathrm{HCl}$ and chondroitin sulphate Equine vet J Suppl 2002, 34:224-229.

55. Shikhman AR, Kuhn K, Alaaeddine $N$ and Lotz $M$ : N-acetylglucosamine prevents IL-I $\beta$-mediated activation of human chondrocytes J Immunol 200I, 166:5155-5I60.

56. Omata $\mathrm{T}$, Segawa $\mathrm{Y}$, Itokazu $\mathrm{Y}$, Inoue $\mathrm{N}$ and Tanaka $\mathrm{Y}$ : Effects of chondroitin sulfate-C on bradykinin-induced proteoglycan depletion in rats Arzneimittel forschung 1999, 49:577-581. 
57. Uebelhart D, Thonar E), Zhang J and Williams JM: Protective effect of exogenous chondroitin 4,6-sulfate in the acute degradation of articular cartilage in the rabbit Osteoarthritis Cartilage 1998, 6(Suppl A):6-13

58. Lippiello L, Woodward J, Karpman R and Hammad TA: In vivo chondroprotection and metabolic synergy of glucosamine and chondroitin sulfate Clin Orthop 2000, 381:229-240.

59. Beren J, Hill SL, Diener-West M and Rose NR: The effect of preloading oral glucosamine/chondroitin sulfate/manganese ascorbate combination on experimental arthritis in rats Exp Biol Med (Maywood) 200I, 226:I44-I5I.

60. Canapp SO Jr, McLaughlin RM Jr, Hoskinson JJ, Roush JK and Butine MD: Scintigraphic evaluation of dogs with acute synovitis after treatment with glucosamine hydrochloride and chondroitin sulfate $A m$ J Vet Res 1999, 60:1552-I557.

61. Leffler CT, Philippi AF, Leffler SG, Mosure JC and Kim PD: Glucosamine, chondroitin, and manganese ascorbate for degenerative joint disease of the knee, or low back: A randomized, double-blind, placebo-controlled pilot study Mil Med 1999, 164:85-91.

62. Drovanti A, Bignamini AA and Rovati AL: Therapeutic activity of oral glucosamine sulfate in osteoarthrosis: A placebo-controlled double-blind investigation Clin Therapeutics 1980, 3:260272.

63. Echard BW, Talpur NA, Funk KA, Bagchi D and Preuss HG: Effects of oral glucosamine and chondroitin sulfate alone and in combination on the metabolism of SHR and SD rats $\mathrm{Mol} \mathrm{Cell}$ Biochem 200I, 225:85-9I.

\section{Pre-publication history}

The pre-publication history for this paper can be accessed here:

http://www.biomedcentral.com/1472-6882/3/2/prepub

Publish with Biomed Central and every scientist can read your work free of charge

"BioMed Central will be the most significant development for disseminating the results of biomedical research in our lifetime. "

Sir Paul Nurse, Cancer Research UK

Your research papers will be:

- available free of charge to the entire biomedical community

- peer reviewed and published immediately upon acceptance

- cited in PubMed and archived on PubMed Central

- yours - you keep the copyright

Submit your manuscript here:

http://www.biomedcentral.com/info/publishing_adv.asp
BioMedcentral 